\title{
Door based Power Generation System and Automatic Opening of Door
}

\author{
Hrishikesh Hinge $^{\dagger^{*}}$ and P. E. Chaudhari ${ }^{\dagger}$ \\ ${ }^{\dagger}$ Department of Mechanical Engineering, MIT College of Engineering, Pune, India \\ Accepted 02 March 2016, Available online 15 March 2016, Special Issue-4 (March 2016)
}

\begin{abstract}
As the world is advance in various fields like research and development; conservation of energy is very important aspect. Due to shortage of electricity in the rural areas as well as developing cities saving of energy is an important factor so we have to save the energy whenever as possible. To conserve energy we have taken the step and introduce a new concept 'ELECTRICITY GENERATION WITH THE HELP OF DOOR'. In this concept conversion of mechanical energy from opening a door into electrical energy for backup power supply is studied. The green energy solution makes use of an everyday occurrence to protect against intermitted power loss. The energy you expend by pushing a revolving door you can convert into electrical energy that is usable. For example at Hospitals, Banks, Post offices, Hotels or the use of door is frequent etc. Our aim is to convert small amounts of human energy into electricity by use of generator. The Revolution Door and Electrical component are of two prototype devices with mechanical/electrical systems that harnesses human motion and redistribute it as electricity. This source of power can be used at the offices, colleges or Hotels and most likely by the Hospitals door operating system. Also by accumulating this low intensity electricity in Batteries, it can be supplied to the Big villages or in towns where there is scarcity of electric supply.
\end{abstract}

Keywords: Energy conservation, Generator, Automatic Door Opening.

\section{Introduction}

Door based power generation unit is specially planned to design and fabricate the conversion unit for utilizing the available non-conventional energy source. That is tremendously available energy in low intensity with ample quantity can be utilized. This machine converts reciprocating motion in to rotary motion. The rotational power is stored in flywheel \& flywheel rotate alternator that generate electricity.

The men coming on the path apply the impact force or thrust on the projected mechanism. This impact pressure energy can be utilized to operate the rack and pinion gearing and through the train of pulleys can operate the fly wheel, which stores the energy and utilizes it for continuous rotation of the generator operating pulley and belt transmission system.

This source of power can be used at the malls, colleges or Hotels and most likely by the Hospitals door operating systems. Also by accumulating this low intensity electricity in Batteries, it can be supplied to the Big villages or in towns where there is scarcity of electric supply.

Method and Apparatus for Generating Electricity, (Luciano Vasija, 2001) the paper discusses a method and an apparatus for generating electricity from the

*Corresponding author: Hrishikesh Hinge ordinarily wasted mechanical energy expended when opening a door. The apparatus includes a ratchet attached to a door which rotates a connecting shaft which opens the door. The connecting shaft is connected by a gear train to a spring housing in which a spiral shaped spring is attached and connected to a spring shaft. The spring shaft is coupled by a second gear train to the driveshaft of a generator. Opening the door causes compression of the spiral plate spring, which causes rotation of the driveshaft of the generator in order to generate electricity when the spring is uncoiled. A stopper engages teeth on the bottom plate of the spring housing to prevent reverse rotation of the spring shaft, when the door is closed.

Utilization of Surplus Energy Using Revolving Doors, (Benjamin b. Bryan, Jr., 1927)

This invention relates to means for utilizing the surplus energy which is expended by persons using revolving doors, turnstiles and the like, by causing that surplus energy to be applied to the generation of power for employment in useful manner. From observation in large buildings equipped with revolving doors, as also at railway stations, ferry houses, amusement parks and other places whose entrances are guarded by turnstiles, a considerable amount of man power, in excess of that required, is communicated in the form of impulses to these devices for their rotation, and that some of this surplus force be 
put into useful effect. Therefore the invention consists of mounting a power wheel co-axially with relation to a revolving element, such as a revolving door or turnstile and providing a pawl on said power wheel for engagement by said revolving element to communicate to the power wheel, the impulses received by the revolving element in the manual operation of the latter. Energy thus imparted to the power wheel is to be transmitted there from by suitable means either for the generation of electricity or otherwise for work purposes.

(Der-Yeong Liu, et al, 2004)This paper presents the effect of door openings of refrigerators/freezers on the energy consumption and compartment temperature variation by experimental approach. Two types of refrigerators/freezers were tested in the study. One is a type of variable frequency operation, while the other is a type of fixed frequency operation. The testing procedure was conducted under the ambient temperatures of $15^{\circ} \mathrm{C}$ and $30^{\circ} \mathrm{C}$, and the door opening operation was carried out by one automatic robotic apparatus in an environmental control room. From the test results, energy consumption of refrigerators or freezers with door opening was found to increase by $10 \%$, compared to the same product without door opening. Based on the compartment temperature variation status during door opening, control strategy was also proposed to improve the efficiency of variable frequency type of refrigerators or freezers. Future study on door opening control methodology can be addressed on usages characteristics, so that it would help to control temperature variation and improve energy utilization by minimizing the effect of door opening.

Multiple Mode of a Compact Wrist. (Hongwei Zhang, 2011) This paper presents the multiple mode control system of a compact wrist, which can work in active mode with position or torque control, or passive mode with wrist-environment interactive force compensation. Passive mode is realized without using mechanical solutions such as a clutch, which not only saves weight and volume of the wrist, but also avoids losing track of the joint's position while switching from passive mode to active mode. The objective is to make the wrist suitable for dexterous manipulation in unstructured environments, such as door opening. A robust adaptive controller is developed for tracking control of the wrist in active mode; and a new interactive force compensation technique is proposed based on force sensor measurement, to enable passive working mode of the compact wrist. A prototype wrist has been developed and experiments have been conducted to validate the proposed design and algorithms.

Savonius Rotors for Electricity Production. (J.L. Menet, 2004) This paper presents a study, carried out with the help of the French Agency of Innovation (ANVAR). It deals with the conception of a small Savonius rotor (i.e. of low power) for local production of electricity. Our challenge was to design, develop and ultimately build a prototype of such a rotor, which was considered as a complete electromechanical system. An optimized configuration was chosen for the geometry of the present prototype. The building data were calculated on the basis of the nominal wind velocity $\mathrm{V}=10 \mathrm{~m} / \mathrm{s}$. Particular care was necessary to choose the appropriate generator, which was finally a rewound conventional car alternator. The whole design of the prototype has confirmed the high efficiency and the low technicality of the Savonius rotors for local production of electricity.

Infiltration Rate through Automatic Doorways (Georgios H. Vatistas et al, 2006) An experimental investigation on infiltration rate through automatic doorways was conducted in an experimental room with three automatic doors. The experimental infiltration rate tested was up to $617 \mathrm{~m}^{3} / \mathrm{hr}$, which was equivalent to the outdoor air occupying about $47 \%$ of the outdoor air supplied to the room. The result of the infiltration rate increases with an increase of indooroutdoor temperature difference. Based on the unbalanced supply-return airflow in a HVAC system, the total infiltration rate was corrected with the combined counter and exfiltration airflow and the air lock exchange to develop a reliable correlation. This correlation enables the prediction of the infiltration rate through an automatic door with the cycling of the door opening and closing.

\section{Need of the System}

There is an impending need to make much more forays to make Non-Conventional energy attain popular acclaim. This is also very essential to preserve the conventional sources of energy and explore viable alternatives like sustainable energy (the energy which we are already utilizing but for some safety of other uses we are suddenly wasting it, that can be reutilized), solar, wind and biomass that can enhance sustainable growth. What is more, such alternatives are environment friendly and easily replenishable. Therefore, they need to be thoroughly exploited with a functionally expedient, energy matrix mix. The engineer is constantly conformed to the challenges of bringing ideas and design into reality. New machines and techniques are being developed continuously to manufacture various products at cheaper rates and high quality. Growing economies, especially of Asia are gifted with sufficient resource base and nonconventional energy technologies are consistent both for grid linked energy generation and transmission in out of the way locales that are islanded from the grid. Adaptation of technology and employing them should be pursued right from this moment to have a head start, be informed of the barriers in technology applications of the renewable variety and synergizing them with the existing, traditional power production technology and T\&D networks. It is known that in coming times, wind energy will be the most costeffective renewable resource. Yet, it is doubtful if any individual technology would hold centre-stage. 


\section{Construction}

In order to design and manufacture, we must take into account various parts that are to be used to fabricate our desired model. (Table. 1)

1. Plate:

The material of plate is cast iron. The plate is placed above the rack and spring. Due to that when the person is walking on the plate the plate is move downward due to weight of person. The weight carrying capacity is below $350 \mathrm{~kg}$. Following are the specification of the plate. (Table 2)

\section{Spring:}

It is define as elastic body whose function is to deflect to deform by storing the energy when loaded and recover its original shape when load is removed. It is made up of wire coil in the form of helix. Cross section of wire will be circular, square, rectangular depending upon the type of load and deflection. The load applied on the spring is along the axis of helix. The major streets in helical spring are shear due to twisting.

3. Door:

The $3 \mathrm{~mm}$ thick metal sheet door is weld to the vertical shaft and at the bottom of the shaft one bevel pinion is attached. And this bevel pinion is mesh with the bevel pinion which is mounting on horizontal bar. The motion of this bevel pinion is get the door through the vertical shaft pinion. Due to that the door is open and closed.

4. Rack And Pinion:

Torque can be converted to linear force by a rack and pinion. The pinion is a spur gear, and meshes with a toothed bar or rod that can be thought of as a sector gear with an infinitely large radius of curvature. Such a mechanism is used in automobiles to convert the rotation of the steering wheel into the left-to-right motion of the tie rod(s).

\section{Spur Gear train:}

A gearbox is not an amplifier or a servomechanism. Conservation of energy requires that the amount of power delivered by the output gear or shaft will never exceed the power applied to the input gear, regardless of the gear ratio. Work equals the product of force and distance; therefore the small gear is required to run a longer distance and in the process is able to exert a larger twisting force or torque, than would havebeenthe case if the gears were the same size. There is actually some loss of output power.

6 Ball bearings:

In ball bearing spherical ball are used in rolling element. The contact between inner race the ball and outer race is point contact. So it is higher pair. In the ball bearing axial dimension is less and radial dimensions are more load carrying capacity is low because of point contact. Inner diameter is $12 \mathrm{~mm}$ and outer diameter is $21 \mathrm{~mm}$.

7. Shaft:

It rotating machine element, it is used to transmit the power from one place to another with the help of pulley or gear. When the shafts are parallel rope drive are used. When the shaft is co-axial then they are connected by coupling used to transmit the power and motion from one shaft to another. Its diameter is $12 \mathrm{~mm}$.

8. V- belt:

It is mostly used in factories and workshops. By this belt moderate amount of power is transmitted. Power is transmitted from one pulley to another pulley only when the distance the distance between pulleys is not more than $8 \mathrm{~m}$ apart. The material used for that belt is lather, cotton and fabric material, flexible rubber, balata belt.

9. Pulley:

It is made for the aluminum and this pulley diameter is $150 \mathrm{~mm}$. The pulley is attached the Stepper motor by using belt drive. When the Spur gear rotates then the pulley is rotated and transfers the motion belt drive through Stepper motor. Then the generate electricity.

10. Bevel Gear:

Bevel gear is made of cast iron, which use to convert horizontal motion in to vertical rotational motion in to angle of 90 degree 15 teeth is present in one bevel gear. Its diameter is $20 \mathrm{~mm}$.

11. L.E.D (Light Emitting Diode):

As name suggested it is forward biased P-N Junction which emits visible light when energy are discussed earlier charge carries recombination takes place when electrons from $\mathrm{N}$-side cross the junction \& recombined of the of P-side. Now electrons in the higher conduction bond on the $\mathrm{N}$-side as holes where as holes in the lower bond on the P-side during recombination some of this energy different and given in the form of Heat and Light.

\section{Mechanical Work \& Electricity Generation:}

It is electro-mechanical energy generating machine. This machine converts reciprocating motion in to rotary motion. The rotational power is stored in flywheel \& flywheel rotates dynamo, which generates electricity.

Here first important point is how we get reciprocating motion, which is prime input in the system. For that we use weight of moving person that waking on path. We put our machine underground of door system, the head of rack is bring up to level of ground surface. When persons weight move on rack it will be pushed down. The rack is attached with free wheel type pinion that rotates in one direction only. The rack \& pinion arrangement convert reciprocating motion in to rotary motion. So spur gear is attached to a pinion the motion transmit through pinion to spur gear the end of spur gear shaft the bevel gear is attached so rotational motion of spur gear shaft is given to the bevel gear the horizontal motion of bevel gear. It is converted in to vertical rotational motion so door is open and closed operation. Then another transmits motion of spur gear is given to the pulley. Pulley will rotate and through the flat belt motion will give alternator the power will be stored in battery we can use this stored energy with the multiple purpose. 


\section{How electricity generates}

Dynamo - a device that makes direct current electric power using electromagnetism (fig 2). It is also known as a generator; however the term generator normally refers to an "alternator" which creates AC power.

The generator/dynamo is made up of stationary magnets (stator) which create a powerful magnetic field, and a rotating magnet (rotor) which distorts and cuts through the magnetic lines of flux of the stator. When the rotor cuts through lines of magnetic flux it makes electricity.

Faraday's Law of Induction states that if we take a wire and move it back and forth in a magnetic field, the field pushes on electrons in the metal. Copper has 27 electrons; the last two in the orbit are easily pushed on to the next atom. This movement of electrons is electrical flow. If you take a lot of wire such as in a coil and move it in the field, we create a more powerful "flow" of electrons

The Dynamo consists of 3 major components: the stator, the armature, and the commutator (fig 1). The stator is a fixed structure that makes magnetic field; you can do this in a small dynamo using a permanent magnet. Large dynamos require an electromagnet. The armature is made of coiled copper windings which rotate inside the magnetic field made by the stator. When the windings move, they cut through the lines of magnetic field. This creates pulses of electric power.

The commutator is needed to produce direct current. In direct current power flows in only one direction through a wire, the problem is that the rotating armature in a dynamo reverses current each half turn, so the commutator is a rotary switch that disconnects the power during the reversed current part of the cycle. Brushes are part of the commutator; the brushes must conduct electricity as they keep contact with the rotating armature. The first brushes were actual wire "brushes" made of small wires. These wore out easily and they developed graphic blocks to do the same job.

\section{Design of Components}

\subsection{Spring}

Type: Helical compression spring

\section{Material:}

Patented and cold working wire- content 0.85 to $0.95 \mathrm{C}$ Given: modulus of rigidity- 81370 N/mm

For application:

Considering Platform weight

\section{Weight of platform:-}

Density of material (MS) $=7.86 \times 10^{3} \mathrm{~kg} / \mathrm{m}^{3}$

Weight of steel plate $(w s)$

$w s=\left(300 \times 10^{-3}\right) \times\left(600 \times 10^{-3}\right) \times\left(2 \times 10^{-3}\right) \times(7850)$

$$
=2.826 \mathrm{~kg}
$$

Weight of two angles $(w a)$

$w a 1=\mathrm{b} \times \mathrm{d} \times \mathrm{t} \times \rho$

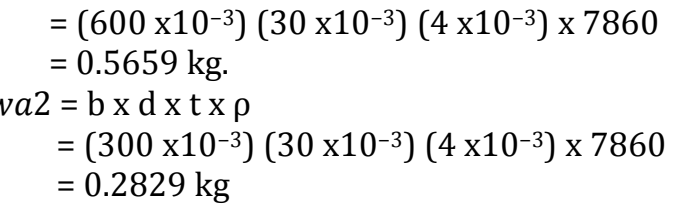

Total weight of platform $=(0.5659 \times 2)+(0.2829 \times 2)$

$$
=1.7 \mathrm{~kg}
$$

Max. Spring force $=(\mathrm{P})=784.8 / 4$

$=196.2 \mathrm{~N}$

\section{Wahl Fact (K):-}

Consider the effect on direct shear stress and stress concentration due to curvature effect.

$\mathrm{K}=(4 \mathrm{C}-1 / 4 \mathrm{C}-4)+0.615 \mathrm{C}$

Spring index $=\mathrm{C}=8$

$\mathrm{K}=4(8)-14(8)-4+0.6158$

$\mathrm{K}=1.26$

\section{Permissible shear stress:-}

$$
\begin{aligned}
\tau & =\mathrm{K}\left[8 \mathrm{PC} / \pi \mathrm{d}^{2}\right] \\
& =\mathrm{K}\left[8 \times 196.2 \times 8 / \pi^{2}\right] \\
& =1.26 \times 8 \times 196.2 \times 8 \pi \mathrm{d}^{2} \\
& =5036.16 / \mathrm{d}^{2} \\
\mathrm{D} & =2.5 \mathrm{~mm} \\
\tau & =5036.16 / 2.5^{2} \\
& =805.78 \mathrm{~N} / \mathrm{mm}^{2} \\
\mathrm{~d} & =2.5 \text { for Sut }=1640 \mathrm{~N} / \mathrm{mm}^{2} \\
\tau \mathrm{d} & =0.5 \mathrm{sut} \\
& =1640 \times 0.5 \\
& =820 \mathrm{~N} / \mathrm{mm}^{2} \\
\tau \mathrm{d} & >\tau \ldots \ldots . . . \text { hence the design is safe. }
\end{aligned}
$$

Mean coil diameter (D):-

$\mathrm{C}=\mathrm{D} / \mathrm{d}$

$\mathrm{D}=\mathrm{Cd}=8 \times 2.5$

$\therefore$ Number of active coils (n)

$\mathrm{D}=20 \mathrm{~mm}$

$\delta=8 \mathrm{PD}^{3} \mathrm{n} / \mathrm{G} \mathrm{d}^{4}$

$$
\begin{aligned}
\therefore \mathrm{n} & =60 \times 81370 \times 2.5^{4} / 8 \times 196.2 \times 20^{3} \\
& =15.18 \\
& \cong 16
\end{aligned}
$$

$\mathrm{d}=2.5 \mathrm{~mm}$

$\mathrm{n} \cong 16$

Assume square and grounded end

Total number of coil $(\mathrm{N} \mathrm{t})$ :-

$$
\begin{aligned}
& \mathrm{Nt}=\mathrm{n}+2 \\
& \quad=16+2 \\
& \begin{aligned}
\mathrm{Nt} & =18 \\
\text { Solid length } & =\mathrm{Nt} \times \mathrm{d} \\
& =18 \times 2.5 \\
& =45 \mathrm{~mm}
\end{aligned}
\end{aligned}
$$

Actual deflection of coil $\left(\delta_{\mathrm{a}}\right)$

$$
\begin{aligned}
\delta_{\mathrm{a}} & =8 \mathrm{PD}^{3} \mathrm{n} / \mathrm{Gd}^{4} \\
& =8 \times 196.2 \times 20^{3} \times 16 / 81370 \times(2.5)^{4} \\
& =63.20 \mathrm{~mm}
\end{aligned}
$$


Free length (Lf):-

$\mathrm{Lf}=$ solid length + total axial gap $+\delta$

Total gap $=(\mathrm{Nt}-1) \times$ gap between two adjacent coils $=(18-1) \times 1$ $=17$

$\therefore \mathrm{Lf}=45+17+63.20$

$=125.2$

$\therefore \mathrm{Lf}=130 \mathrm{~mm}$.

Pitch of coil $(\mathrm{p})$ :-

$\mathrm{p}=$ free length $/(\mathrm{Nt}-1)$

$=120 / 17$

$=7.64 \mathrm{~mm}$

$$
\begin{aligned}
\mathrm{K} & =\mathrm{P} / \delta \\
& =784.8 / 60 \times 4=3.27 \mathrm{~N} / \mathrm{mm}
\end{aligned}
$$

Actual spring rate is given by,

$\mathrm{K}=\mathrm{G} \mathrm{d}^{4} / 8 \mathrm{D}^{3} \mathrm{n}$

$=81370 \times 2.5^{4} / 8 \times 20^{3} \times 16=3.10 \mathrm{~N} / \mathrm{mm}$

Required spring rate without load:-

$\mathrm{K}=40.8 / 4 \times 60=0.17 \mathrm{~N} / \mathrm{mm}$

\section{Dimensions of Gear:-}

1) Number of teeth on pinion $=Z p=20$ teeth

2) Number of teeth on gear $=\mathrm{Zg}=42$ teeth

3) Module $\mathrm{m}=2 \mathrm{~mm}$

4) Face width $b=20 \mathrm{~mm}$

5) Pitch circle dia. of pinion $\mathrm{dp}=40 \mathrm{~mm}$

6) Pitch circle dia. of pinion $\mathrm{dg}=84 \mathrm{~mm}$

7) Addendum $\mathrm{m}=2 \mathrm{~mm}$

8) Dedendum $(1.25 \mathrm{~m})=1.25 \mathrm{x} 2=2.5 \mathrm{~mm}$

9) Clearance $0.25 \mathrm{~m}=0.25 \times 2=0.5 \mathrm{~mm}$

10) Tooth thickness $1.57 \mathrm{~m}=1.57 \times 2=3.14 \mathrm{~mm}$

11) Fillet radius $0.4 \mathrm{~m}=0.8 \mathrm{~mm}$

\section{Dimensions of Bevel Gear:}

1) $m=2 m m$

2) $b=4 \mathrm{~m}=4 \times 2=8 \mathrm{~mm}$

3) $\mathrm{dP}=\mathrm{m} \cdot \mathrm{ZP}=2 \times 15=30 \mathrm{~mm}$

4) $d G=m \cdot Z G=2 \times 15=30 \mathrm{~mm}$

5) $\mathrm{Ao}=10.6 . \mathrm{m} 10.60 \times 2=21.2 \mathrm{~mm}$

6) ha= $1 \mathrm{~m}=2 \mathrm{~mm}$

7) $\mathrm{hf}=1.25 \mathrm{~m}=1.25 \times 2=2.50 \mathrm{~mm}$

8) $\mathrm{fd}=92.92 \mathrm{~N}$

9) $\mathrm{BHN}=421.91$

10) Diameter of shaft $=12 \mathrm{~mm}$

\section{Working of Model}

Here first important point is how we get reciprocating motion, which is prime input in the system. For that we use weight of moving person that waking on path. We put our machine underground of door system, the head of rack is bring up to level of ground surface. When persons stands on platform it pushes rack down. The rack is attached with free wheel type pinion that rotates in one direction only. The rack \& pinion arrangement convert reciprocating motion in to rotary motion.
So spur gear is attached to a pinion the motion transmit through pinion to spur gear the end of spur gear shaft the bevel gear is attached so rotational motion of spur gear shaft is given to the bevel gear the horizontal motion of bevel gear. It is converted in to vertical rotational motion so door is open and closed operation. Then another transmits motion of spur gear is given to the pulley. pulley will rotate and through the flat belt motion will give alternator (fig. 2) the power will stored in battery we can use this stored energy with the multiple purpose. (Fig. 3)

\section{Testing Of Model}

\subsection{Observation}

When 1 person passes from the platform

Number of revolutions obtained $=1$

Average output Voltage $=12 \mathrm{~V}$

Average output current $=0.1$ Amp (Table 3)

\subsection{Total power generation}

When 1 person passes from the platform,

Number of revolutions obtained $=1$

For 1 revolution, electricity generated $=12 \mathrm{~V}, 0.1 \mathrm{Amp}$

$\therefore$ For $1 \mathrm{rev} .=12 \mathrm{~V}$ x $0.1 \mathrm{Amp}=1.2 \mathrm{~W}$

Consider that in one minute 5 persons passing through the platform $=1.2 \times 5=6 \mathrm{Watt}$

$\therefore$ In 1 hour $=6 \times 60=360$ watt

Consider that in a day, door is operated for 16 hours

$\therefore$ Power generated in a day $=360 \times 16$

$$
=5760 \mathrm{watt}
$$

$$
=5.76 \mathrm{KW} \text {. }
$$

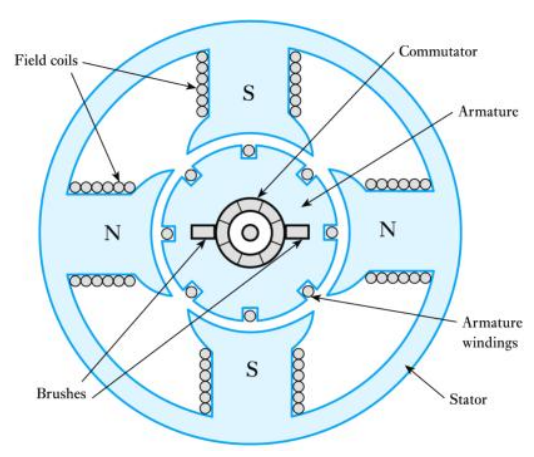

Fig.1 Construction of DC Generator

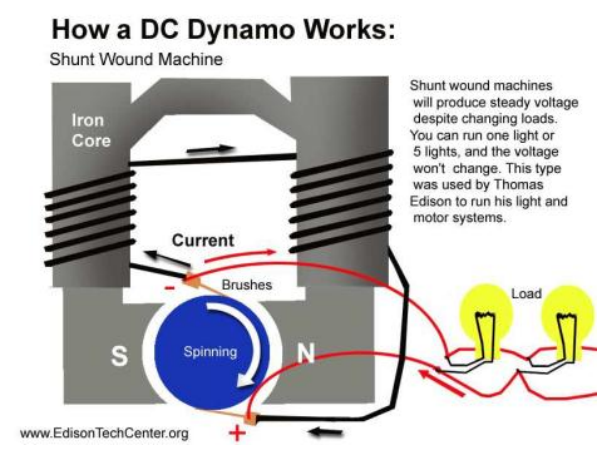

Fig.2 Working of Dynamo 


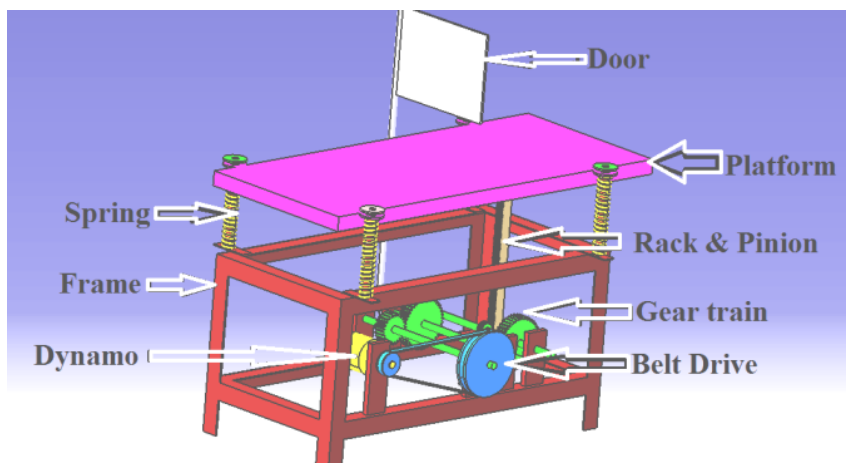

Fig. 3 Working of Model

Table 1: Part List

\begin{tabular}{|c|c|c|}
\hline Sr. No. & Component Name & Quantity \\
\hline 1 & Plate & 1 \\
\hline 2 & L- section angle bar & 13 \\
\hline 3 & Spring & 4 \\
\hline 4 & Door & 1 \\
\hline 5 & Rack & 1 \\
\hline 6 & Flywheel & 1 \\
\hline 7 & Spur Gear & 4 \\
\hline 8 & Ball Bearing & 8 \\
\hline 9 & Shaft & 4 \\
\hline 10 & Dynamo & 1 \\
\hline 11 & V- Belt & 1 \\
\hline 12 & LED strip & 1 \\
\hline 13 & Pulley & 1 \\
\hline 14 & Bevel Gear & 2 \\
\hline
\end{tabular}

Table 2: Platform Details

\begin{tabular}{|c|c|c|}
\hline No. & Parameter & Size in $\mathbf{~ m m}$ \\
\hline 1 & Length & 600 \\
\hline 2 & Width & 300 \\
\hline 3 & Thickness & 5 \\
\hline
\end{tabular}

Table 3: Observation Table

\begin{tabular}{|c|c|c|c|}
\hline $\begin{array}{c}\text { Reading } \\
\text { no. }\end{array}$ & Voltage (V) & $\begin{array}{c}\text { Current } \\
\text { (Amp) }\end{array}$ & Power (W) \\
\hline 1 & 11.86 & 0.095 & 1.1267 \\
\hline 2 & 12.08 & 0.11 & 1.3288 \\
\hline 3 & 12.14 & 0.098 & 1.1897 \\
\hline 4 & 12.16 & 0.10 & 1.216 \\
\hline 5 & 12.14 & 0.089 & 1.086 \\
\hline
\end{tabular}

\section{Conclusions}

The need of designing and manufacturing such a system, which will make the Door operation somewhat flexible, also the energy being absorbed by the generation system will be utilized to convert it in to electricity.

We came to know that how the actual power can be generated with the help of working of the dynamo used in our project. We were able to understand the basic concepts of the components as well as we had come through the standard design procedures that we had followed in our project. We had understood and experienced the manufacturing and fabrication done for the model.

Also we had the automatic door operation that is closing and opening of the door. At the same time reduced the cost of sensors used in automatic doors.

\section{References}

LucianoVasija, (May 22, 2001), Method of Generating Electricity, US-6236118.

B B. Bryan, (April 12, 1927), Utilization of Surplus Energy Using Revolving Doors, US-1624656.

Hongwei Zhang, Yugang Liu, Guangjun Liu, (July 3, 2011), Development of a Compact Wrist with Multiple Working Modes, 2011 IEEE/ASME.

J.-L. Menet, (21 February 2004), Adouble-step Savonius rotor for local production of electricity: a design study, ELSEVIER

Der-Yeong Liu, Wen-Ruey Chang *, Jian-Yuan Lin, (accepted 9 January 2004), Performance comparison with effect of door openingon variable and fixed frequency refrigerators/freezers, ELSEVIER.

Georgios H. Vatistas a, Dekang Chen b, ${ }^{*}$, Tzu-Fang Chen a, Sui Lin a, (5 June 2006), Prediction of infiltration rates through an automatic door, ELSEVIER. 